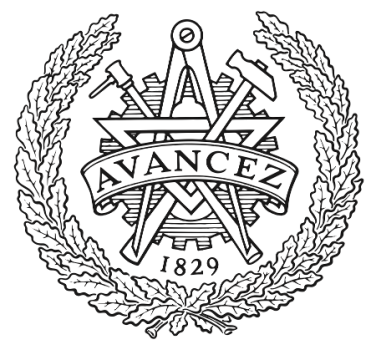

CHALMERS

UNIVERSITY OF TECHNOLOGY

\title{
Life cycle work: A process study of the emergence and performance of life cycle practice
}

Downloaded from: https://research.chalmers.se, 2023-04-26 14:52 UTC

Citation for the original published paper (version of record):

Lindén, H., Diedrich, A., Baumann, H. (2021). Life cycle work: A process study of the emergence and performance of life cycle practice. Organization and Environment, 34(1): 99-122. http://dx.doi.org/10.1177/1086026619893971

N.B. When citing this work, cite the original published paper. 
Life cycle work: A process study of the emergence and performance of life cycle practice

Hanna Nilsson-Lindén ${ }^{\mathrm{a}, \mathrm{c*}}$, Andreas Diedrich ${ }^{\mathrm{b}}$, Henrikke Baumann $^{\mathrm{a}}$

aEnvironmental Systems Analysis, Chalmers University of Technology, 41296 Gothenburg, Sweden

${ }^{\mathrm{b}}$ Gothenburg Research Insitute, School of Business, Economics and Law, University of Gothenburg,

Viktoriagatan 13, SE-411 25 Gothenburg, Sweden

'RISE Research Institutes of Sweden, RISE IVF, Argongatan 30, SE-431 22 Mölndal, Sweden

*hanna.linden@ri.se, $0046(0) 102284675$

https://doi.org/10.1177/1086026619893971

\begin{abstract}
Life cycle management (LCM) is a concept that goes beyond traditional corporate environmental management, due to its' focus on a product's entire life cycle. The spread of such concepts is usually understood in terms of processes of 'diffusion', whereby ideas spread over time by some inexplicable force. However, diffusion has proven less adequate to describe how ideas spreads in practice. Here, we address this oversight by studying the emergence and performance of what we refer to as life cycle practices. Drawing on an analysis of the development of a sustainability portfolio within a globally-operating manufacturing company, we illustrate the kinds of life cycle work involved in dealing with local activities and interests, connecting activities and interests into action-nets, performing life cycle practices, and spreading the life cycle idea. Finally, we discuss implications of life cycle work for research in the field of organization and management studies and for LCM research.
\end{abstract}

Life cycle management (LCM), action-nets, sustainability, sociology of translation, performativity

\title{
Introduction
}

It has recently been suggested that climate change and other complex sustainability challenges are bound to reshape company supply chains in the future (Howard-Grenville, Buckle, Hoskins, $\&$ George, 2014). These developments continue to give rise to a range of new concepts and models seen as effective solutions for companies wishing to implement more sustainable business practices. One such concept that has received increased attention is life cycle management (LCM), which has been widely seen as providing a holistic and interconnected perspective on environmental impact throughout the product life cycle, extending from raw material extraction to product end of use (see, e.g., Remmen, Jensen, \& Frydendal, 2007; Sonnemann \& Margni, 2015), rather than environmental concerns residing in single organizations or production sites. The focus of such more individual corporate focused environmental management might reside more in environmental management systems, or other issues related more directly to the company, rather than in the total environmental impact of the product. The benefit of LCM is assumed to be the explicit link it creates between companies and their natural resource use and pollutant emissions throughout the product chain (see Ehrenfeld, 1997). Other commentators have gone so far as to suggest that LCM is "unlocking 
the circular economy" (Colens, 2017), facilitating the transition from the traditional linear economy to a more sustainable development.

Given the importance attached to LCM, it is important to understand how LCM is practiced in organizations. In particular, how do such practices emerge, and how are they performed over time as part of ongoing processes of organizing?

Efforts to establish sustainable business practices and processes go hand in hand with processes of organizational change, as new sustainability concepts, ideas, and models get picked up by members of organizations and need to be translated into practice and be integrated into day-today business activities (Millar, Hind, \& Magala, 2012). However, we still know surprisingly little about how such processes of translation unfold over time within the organizations were ideas get picked up to be further translated. The aim of this paper is to explore the complexities emerging as part of such change efforts. More specifically, we explore the attempts to establish LCM as a viable solution to the 'sustainability challenge' in a multinational manufacturing company, drawing on a sociology of translation approach (Latour, 1986; 1987; 2005) and its use in the field of management and organization studies (Czarniawska, 2004; 2008; Gehman et al., 2013). By doing so we are able to move from a normative understanding of the life cycle and LCM as given once and for all, towards a performative understanding of LCM as temporary, fluid and situated in organizing practices.

The paper is based on a study of the development of LCM at ManuCorp, a globally-operating industrial manufacturing company in Scandinavia, over a seven-year period. Based on our analysis, we propose the concept of life cycle work comprising four important and interrelated processes, starting with: 1) handling local activities and interest, followed by 2) connecting local activities and interests into action-nets, into 3) performing life cycle practices, and 4) spreading the life cycle idea. Our findings show that LCM is the (temporary) outcome of reciprocal processes of translation as part of which stakeholders inside and outside of the organization interact with one another, enact activities and to produce texts about the company being environmentally friendly and intended for its stakeholders and for other uses. As part of these processes, translation combines elements of idealistic discourse justifying change with strategies that contextualize and legitimize new organizational activities.

These insights contribute to an understanding of the efforts involved in the emergence and act of performing of life cycle practices as well as the efforts that life cycle practices perform and provoke in organizations. We round off by discussing some implications of life cycle work for future research in the field of organization and management studies.

\section{LCM and its management in organizations}

Companies engaging in sustainable business practices often do so with a focus centering on the environmental and/or sustainability perspective of the individual organization. However, the LCM perspective has been described as "going beyond the traditional focus on single production sites and manufacturing processes so to include environmental, social and economic impact of a product over its entire life cycle" (Remmen et al., 2007, p. 12; Bey, 2018). The idea 
is a holistic perspective on environmental management in the whole product life cycle (i.e. from raw material extraction through to product end-of-life), and a logic of minimizing the total environmental impact of a product, independent of the place of occurrence in the product chain (e.g. Hunkeler et al., 2003; Baumann \& Tillman, 2004; Poikkimäki, 2006; Sonnemann, Gemechu, Remmen, Frydendal, \& Jensen, 2015), whilst also ensuring the absence of suboptimizations (e.g. Welford, 2003; Baumann \& Tillman, 2004; Bey, 2018). One, out of several definitions, propose LCM to be a "product management system aiming to minimize environmental and socioeconomic burdens associated with an organization's product or product portfolio during its entire life cycle and value chain. As a management concept, LCM includes both formalized structures and social practices within the organization and in its external relations" (Remmen et al., 2007, and modified by Schmidt, 2013).

The traditional way for companies to manage environmental concerns has been to focus on the environmental aspects related to a company's production, rather than on the supply chain or the products as these are used (Rebitzer, 2015), sometimes referred to as corporate environmental management (see Meima, 2002). However, with tools such as life cycle assessment (LCA) it has been shown that environmental impacts of company activities often occur elsewhere in the product life cycle (see Ehrenfeld, 1997), in LCA referred to as 'hotspots' (Baumann \& Tillman, 2004). The LCM concept is thus proposed as an approach for companies to manage these environmental impacts (e.g. Remmen et al., 2007; Sonnemann \& Margni, 2015), and to serve as an analytical framework which takes a broad perspective of ecological thinking (Ehrenfeld, 1997), and can act as a guiding logic for action (Heiskanen, 2002). This logic has its basis in the total environmental performance of the product life cycle, which sometimes, but not necessarily, is assumed to fit well with independent business logics of separate companies in the product chain. LCM is thus seen as providing a broad and systemic environmental approach.

Further, LCM is also described as a toolbox (see, e.g. Poikkimäki, 2006; Sonnemann \& Margni, 2015). Within that toolbox, LCA is an often-used tool. LCA is a method for, in quantitative terms, describing natural resource use and pollutant emissions (i.e. environmental impact) across the whole product life cycle (Baumann \& Tillman, 2004). It provides, among else, a way of determining the environmental state of a product system, compare the environmental performance of alternative products, and provide data for targets and indicators (Bey, 2018). The LCA procedure may involve several steps, such as defining the product to study, illustrating the life cycle model, calculating emissions and consumed resources, relating emissions/resources to multiple environmental problems (e.g., land use, global warming, ozone depletion, and toxicity), and comparing the various environmental impacts (Baumann \& Tillman, 2004).

Other examples of tools which are frequently mentioned in literature include for example design for environment, key performance indicators, design for recycling, and other tools that take a life cycle consideration (see, e.g. Westkämper, Alting, \& Arndt, 2001; Remmen et al., 2007). With such tools, efforts are made to reduce the environmental performance of products and production along the product or service life cycle, for example, by reusing products or parts 
of products, repairing of products, recycling of material, reduction of energy or material consumption, replacing harmful substances and/or rethinking product design and function (e.g. Remmen et al., 2007).

The LCM 'toolbox' is afforded a prominent role in discussions on LCM, both at LCM conferences and in the literature (see, e.g. Finkbeiner, 2011; Sonnemann \& Margni, 2015; Benetto, Gericke, \& Guiton, 2017). When discussing LCM, 'implementation' is a highlighted topic (see, e.g. Linnanen, Bostrom, \& Miettinen, 1995; Hellweg, Koehler, \& Rebitzer, 2008; Sonnemann \& Margni, 2015). Here, reoccurring topics include for example the need of top management support, development of strategic goals, explicit communication in the organization, active involvement and collaboration of employees from all functions of the organization, and clear connection to economic gains (e.g. Remmen et al., 2007; Sonnemann \& Margni, 2015; Strothmann, Bricout, Sonnemann, \& Fava, 2015) or 'diffusion' (e.g. Hoffman, 2001). Also, focus tends to reside in descriptions of 'good examples' (e.g. Remmen et al., 2007; SLC report, 2016) and prescriptions of how to conduct LCM (Nilsson-Lindén, 2018). The anticipation is thus rational choices and actions and to the 'automatic' spread of ideas throughout organizations. As Rex (2008) noted, LCM literature tends to take a functionalistic view on LCM, viewing it mainly as a stepwise process, "resulting in heavy emphasis on standards, tools, databases, and guidelines" (p. 55). As such, literature on LCA is much more frequent than literature on adoption factors for LCM (Mortimer, 2011), which in turn implies that, less is known on how LCM is 'implemented' in practice.

However, a smaller group of researchers within the field of LCM has explicitly drawn on social sciences to understand LCM development in industry, advocating to understand LCM as an organizational problem rather than a technical one (Rex, 2008), and proposing LCM to include social practices (Schmidt, 2013). A social science perspective on LCM has for example been proposed as a way of explaining 'how', in addition to 'what' LCM is and is performed (Hoffman, 2003). Such studies have shown that identical recommendations for implementation of LCA and LCM becomes inapplicable, as organizations differ and translate these guidelines differently (see, e.g. Baumann, 2000; Heiskanen, 2000; Rex \& Baumann, 2007).

To sum up, LCM research tends to be categorized in terms of 'implementation' (see, e.g., Hellweg et al., 2008) or 'diffusion' (see, e.g., Hoffman, 2001), with only few examples of LCM understood as social practices. Consequently, it remains difficult to understand the processes through which life cycle practices emerge and are performed in organizations.

\section{Introducing a translation perspective}

The normative approaches to LCM in organizations define the concept in ostensive terms (Latour, 1986) - as given, once and for all. By contrast, other scholars have argued for a more dynamic and performative understanding of organizing (Weick, 1979; Czarniawska, 2008). When applied to the study and understanding of LCM in organizations, this perspective suggests the need to focus on processes whereby LCM emerges in ongoing performances. Thus, understanding what is LCM, why it is LCM, and how it is made recognizable as LCM requires focus on the practices through which LCM is performed. 
In this paper, we mobilize a sociology-of-translation-inspired approach to organizing (Czarniawska \& Joerges, 1996; Czarniawska \& Sevón, 1996; 2005; Czarniawska, 2004; 2008; Diedrich et al. 2013; Gehman et al. 2013), and treat the emergence and performance of LCM as ongoing processes of translation consisting of a number of key organizing processes. This approach to the sociology of translation originates from a combination of actor-network theory (ANT) and new institutional theory (see Wæraas \& Nielsen, 2016, for a comprehensive review of different translation approaches used in the organization and management studies). While early ANT scholars examined existing networks based on their interest in the history of science and technology, the sociology of translation as applied to management and organization studies takes a step back in time to explore how organizing unfolds before stabilized arrangements referred to as 'networks,' 'organizations,' or 'innovations' are in place and discernable.

Such organizing, suggested Barbara Czarniawska (2004), can be conceptualized as the formation and maintenance of action nets. Incorporating insights from new institutional theory (DiMaggio \& Powell, 1983), the concept of action nets suggests that organizing involves processes of connecting actions that are understood to be a requirement for a specific purpose and as legitimate in a specific institutional order. But connecting actions into nets demands the translation of various actions and interests into others, and the stabilization of nets requires the work not only of humans, but also of objects. Thus, an action net is an ongoing accomplishment and if the connections are stabilized and actions are repeated over time, they become institutionalized. Such a perspective, she suggests, shifts the focus from who does what to what is actually being done (Czarniawska, 2005). An action net may involve a variety of organizations or organized groups of people of a loose or temporary nature (Lindberg \& Czarniawska, 2006).

The management and organization studies, however, have continued to focus on 'actors and their network(s)', a company and its customers, suppliers, consultants, owners, partners who establish a strategic alliance, for instance, and to neglect the action nets that have produced the actors and their network(s). This makes it difficult, if not impossible, to understand why these particular actors play a part and what connects them to one another. Is it a company's vision or strategic plan that has afforded an actor a central position? Or, could it be that a personal contact, an unforeseen event or a routine act is responsible?

The approach of studying organizing as the formation and maintenance of action nets directs attention to how organizing practices emerge and are performed as part of ongoing processes, to how battles are fought over the meaning and shape of existing institutional arrangements, to the processes through which ideas are translated locally, and to efforts to legitimize new ways of doing things and new practices (Czarniawska \& Sevón, 1996; Callon, 1998; Gehman et al., 2013). Studying 'values practices' - practices that are considered as normatively right or wrong and thus pursued as ends in themselves in organizations, Gehman et al. (2013) identified four key processes in such translations: a) the emergence of 'pockets of concern' - localized interests and activities - in ongoing interactions between actors throughout an organization, $b$ ) the 'knotting' of these local concerns into networked arrangements of actions, c) the performing of the practices, when they not simply describe what should be said or done, but 
intervene actively in ongoing organizing thereby 'contributing to the enactment of normative realities' (Gehman et al. 2013), and finally d) the intended and unintended spreading of life cycle discourse throughout the organization and beyond, among actors interconnected by the product life cycle.

The notion of translation here captures the movement of an entity in space and time through which connections, associations and relationships are established due to the active work of heterogeneous mediators such as people, models, strategy documents, images, stories, reports, and contracts (Latour, 2005) that carry meaning and interests. It also signals that this movement from one context to another always implies a shift in meaning, a transformation implicit in any translation from one language to another. As actors from the outset each bring with them their own diverse interests, the stabilization of any form of association or relationship depends on the ability to translate, that is, re-interpret, re-present, or appropriate, others' interests in terms of one's own through processes of negotiation (Callon, 1986; Bergström \& Diedrich, 2011). Translation therefore always concerns politics and diverse interests, in that the establishing and stabilizing of associations always involves pursuing specific interests, creating differences, and sustaining unequal power relationships (Nicolini, 2010).

After a certain point, the circulation of ideas depends on the establishment and stabilization of networked processes of organizing involving human and non-human actors (e.g. objects). The emergence of such networked organizing processes often results from a combination of serendipity and intentional efforts (see Callon, 1986; Nicolini, 2010; Bergström \& Diedrich, 2011). Their emergence depends on constant negotiations and mediations through which relevant actors and interests are enrolled and the dissidents are excluded, gradually resulting in stronger networked relationships and dependencies. When such networked relationships grow enough, the emerging action net (Czarniawska, 2004; 2008) can no longer be ignored. It becomes an object of imitation and eventually a source of normative pressure (Nicolini, 2010).

'Corporate environmental management' and 'LCM' can thus be seen as the temporary products of ongoing processes of translation embedded in discourses on the role of companies in society and involving multiple actors. This process implies that while some ideas become repeated and then institutionalized practices, others are dropped as new translations are made. While translation emphasizes the role of actors and interests in actively translating ideas into actions for their own purposes, little is known about how or why a particular idea is rendered appropriate such that it can then be translated into work practices. Indeed, examples of stages of translation of management ideas are rarely offered. For this reason, it has been argued that the translation process needs to be studied at different levels, but particularly at the company level, where active translation occurs (Bjarnar \& Kipping, 1998).

Given this need to study translation processes at company level, in this paper, we aim to explore how LCM emerges and is practiced in an organization. Also, drawing on a sociology of translation approach, we explore the attempts to establish LCM as a viable solution to the 'sustainability challenge' in a multinational manufacturing company. 


\section{The study's setting and method}

\section{The setting}

The empirical material of this paper was collected at ManuCorp, a large, globally-operating industrial manufacturing company positioned in a mainly business-to-business context. ManuCorp manufactures a wide range of products and services, mainly components, and has customers in multiple product segments. The company has made explicit claims regarding LCM, stating its ambition to use LCM to integrate sustainability into its internal core business processes and to reduce environmental impact in its own operations as well as in operations upstream and downstream in its product chains. Additionally, ManuCorp has received several awards for its sustainability work, and has also partnered with nongovernmental organizations with the aim of establishing more sustainable business operations.

We selected ManuCorp because of the access it afforded us, as well as the possibility it gave us to observe and document the processes involved in the emergence and performance of LCM. We attempted to understand life cycle practices in the following way: first, in processual terms, as unfolding over time (Van de Ven \& Poole, 1995; Langley, 1999). Second, and consistent with translation sociology, we concentrated on the controversies when existing life cycle practices became problematized (Latour, 2005). Third, we followed the socio-material elements that were 'enrolled' (Callon, 1986) as life cycle practices were made to work, as well as the efforts required to put in place and stabilize the connections (Czarniawska, 2004).

\section{The method}

To trace the development of life cycle activities within the company, we used empirical material gathered as part of a longitudinal qualitative study between 2011 and 2018 by means of document analysis, interviews and observations. The documents collected comprise ManuCorp's annual reports published over a period of 15 years (2000-2014), LCA/LCM studies published by the company (or in collaboration with the local university), and newspaper articles about ManuCorp (see Table 1). In addition to collecting documents, one of the authors undertook semi-structured interviews with 28 ManuCorp employees during a period of six years (see Table 1). The interviews lasted in average 1-1.5 hours each. Open-ended questions were used, allowing for follow-up questions and detailed discussions (see Charmaz, 2006). The interviews were exploratory in nature and aimed at understanding the activities and initiatives relating to LCM at the company. The interview questions sought to provide details on both, the everyday working activities of the company's employees, as well as the different initiatives, programs and policies that were undertaken. As such, the interviewees were asked to describe a) their position in the organization and their everyday work and how this has changed over time, b) their roles and assignments related to issues concerning the environment, sustainability and/or LCM, c) internal and external collaboration, d) to provide exemplifications and details regarding events and developments, e) to describe issues considered important in their work, f) previous and current state of work as well as a perceived future state of work with environment, sustainability and/or LCM in the organization, and g) suggestions regarding a hypothetical 'do-over'. During the interviews, the interviewees were asked to provide examples and anecdotes where possible. Moreover, the same author also conducted observations at 
ManuCorp during the study time period for one day a week on average. During these visits, it was possible to observe everyday work at ManuCorp (involving to a great extent sustainability staff at the Corporate Sustainability function) and to study the conversations, the planning, and the tinkering that took place.

The interviewees included managers and project managers working with among other things LCM, LCA, sustainability issues, ManuCorp's sustainability strategies, and initiatives such as "Environment, Health and Safety", "Sustainable Supply Chain Management", "Purchasing" and "Sustainable Purchasing". All but three of the interviews were audio-recorded and transcribed (see Silverman, 2011), while notes were taken during the remaining interviews, which were not audio-recorded. 
Table 1. Details regarding empirical data collection of data. Interviewee marked * indicates that $\mathrm{s} /$ he has been interviewed several times

\begin{tabular}{|l|l|l|l|l|l|}
\hline & \multicolumn{2}{|l|}{ INTERVIEWS } & \multicolumn{2}{l|}{ DOCUMENT STUDIES } \\
\hline & $\begin{array}{l}\text { No } \begin{array}{l}\text { Time } \\
\text { interviewees }\end{array} \\
\text { Type of position }\end{array}$ & $\begin{array}{l}\text { No } \begin{array}{r}\text { of } \\
\text { interviews }\end{array} \\
\text { documents }\end{array}$ & Type of document \\
\hline & 1 & Corporate EHS manager & 2012 & 15 & Annual reports \\
\hline & Corporate sustainability manager* & 2012,2017 & 14 & $\begin{array}{l}\text { Published company LCA/LCM } \\
\text { studies }\end{array}$ \\
\hline & 2 & Corporate sustainability project manager & 2012,2014 & & \\
\hline & 1 & Division sustainability manager & 2012 & & \\
\hline & 1 & Sustainable supply chain manager* & 2012,2014 & & \\
\hline & 2 & Sustainability coordinator* & 2011,2012 & & \\
\hline & 1 & Sustainability representative & 2012 & & \\
\hline & 2 & Sustainability research manager* & 2012,2017 & & \\
\hline & 1 & Business manager & 2012 & & \\
\hline & 8 & Pead of Purchasing & 2014 & & \\
\hline & 1 & Sustainable purchasing manager & 2015 & & \\
\hline & 4 & Purchasing project manager & 2015 & & \\
\hline
\end{tabular}


The selection of one company provided the possibility of collecting and comprising extensive empirical material. As such, this study favors 'thick' descriptions of data over generalizability (see Flyvbjerg, 2006). This approach is in line with recommendations of sociology of translation, as innovations are considered 'local', and specific to the specific organization. Further, such thick empirical data is suggested as the aim of social science, as it provides a "more nuanced understanding of the world, and [does] not offer simplified answers to complex questions" (Nicolini, 2012, p. 215). Therefore, a case study approach provides rich details of innovations and translations taking place. The specific case in question provides also a good ground for exploration, as the case company has worked with LCA and LCM for a long period of time and has explicit and official claims of doing LCM.

As a first step of the analysis, we applied a narrative strategy (Langley, 1999), in which we created a chronological empirical narrative of the different life cycle-related activities at the case company, allowing the "construction of a detailed story from the raw data" (p. 695). In parallel, we constructed a visual mapping (Fig. 1), allowing the presentation of large amounts of empirical data in a limited space (Langley, 1999). In the visual mapping, LCM activities at ManuCorp were depicted along a timeline (1995-2015), allowing data reduction and facilitating an overview of the empirical data. It also enhanced the possibility of analyzing the material, as it allowed the identification of "parallel processes, and the passage of time" (Langley, 1999, p. 700).

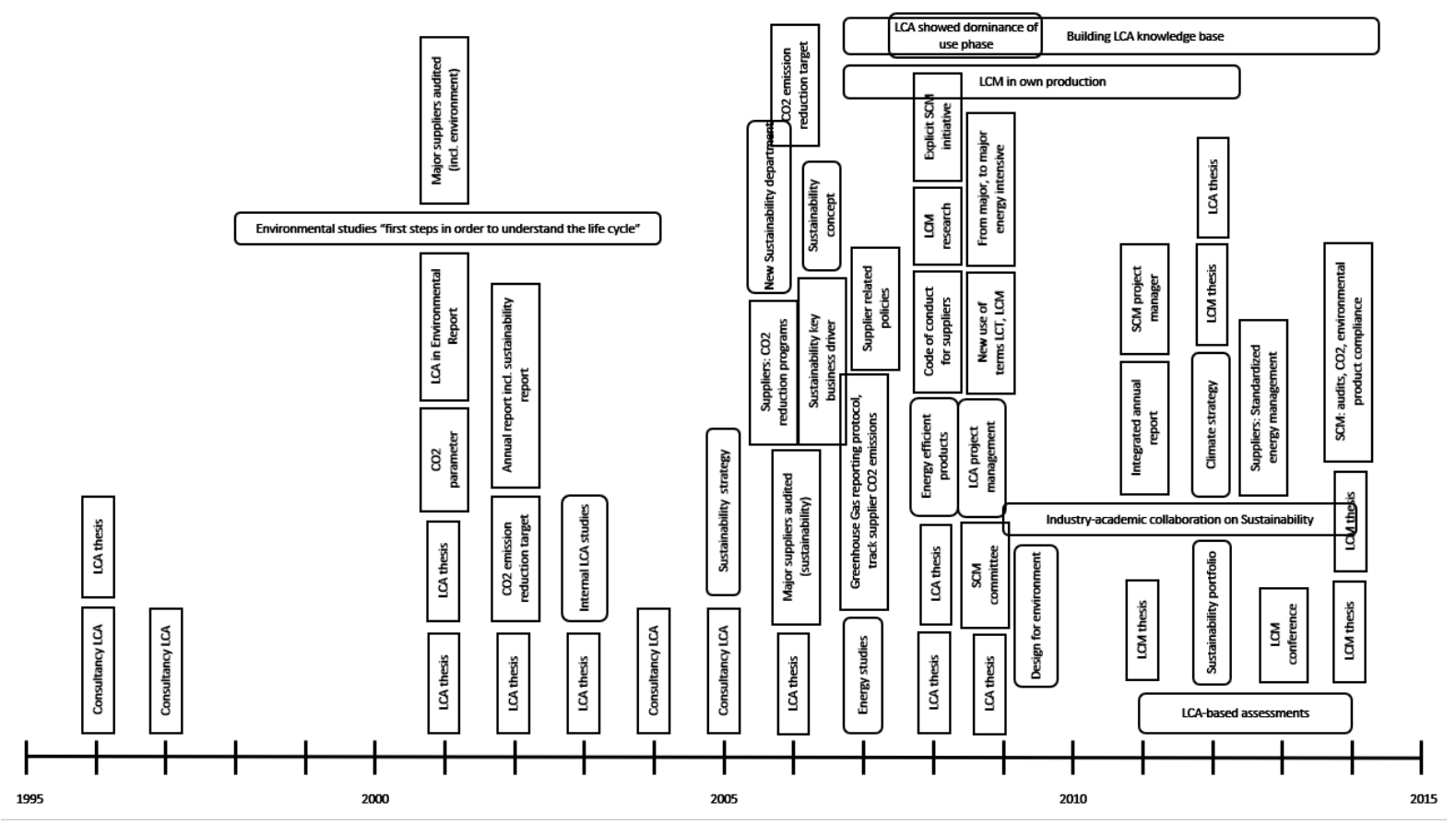

Fig. 1: Visual mapping of the empirical data, ranging from 1995 to 2015. The mapping is based on empirical material and shows different life cycle-related activities taking place at ManuCorp, and the timeline for these events. 
The authors sought to find traces of the life cycle perspective in company material and then to follow these traces over time. The visual mapping of life cycle related activities and events at ManuCorp (Fig. 1) reveals the translation of the life cycle idea from its first traces in master theses (i.e. "LCA thesis") and consultancy reports commissioned by the company and covering topics that were of interest to ManuCorp, to the subsequent development of a "sustainability strategy", a "climate strategy", a "design for environment" and further and steadily multiplying attempts at establishing different life cycle-related activities.

In the final stage, following what Langley (1999) referred to as a 'temporal bracketing strategy' for process theorizing, we composed our empirical material into successive, adjacent periods. These periods do not have any theoretical importance and are not phases in any given sequential process, according to Langley (1999), but simply a way of creating some structure in the description of events. Correspondingly, we were able to explore how activities during one period led to changes in the context that affected activities during subsequent periods. We synthesized Barbara Czarniawska 'action nets' approach to organizing and Gehman et al's (2013) four key processes of the emergence and performance of organizational practices into an analytical heuristic to organize the empirical material according to how the effects stipulated by the four key processes of translation had been achieved. This entailed the chronological structure of the data being broken up. We started by exploring the local activities and interests connected to different locations in the organization and organized them in terms of how they could be seen as having been dealt with by various actors long before LCM emerged at ManuCorp. These activities and interests did not become connected to one another immediately as they emerged in different time/spaces. Activities and interests eventually became connected into an action net until years later. As this happened, LCM gained in strength as a possible tool for encompassing and addressing the local and situated interests (Lindberg \& Czarniawska, 2006). Furthermore, our analysis shows how connecting activities and interests into action nets is just one part of the story. Even after such connecting takes place, life cycle work continues: it is performed, and it performs. In a final move, we put together an overall narrative to show how the connecting of activities and interests among some actors was linked to, and dependent upon the connecting of others, thus allowing us to describe the chain of connections that characterized the four key processes.

\section{The findings}

In the following, we present our findings by first presenting some of the diversity of activities and interests situated at a local level throughout ManuCorp and then showing how some of these activities and interests become connected to each other to form action nets. Finally, we show that such action nets are temporary and fluid in nature and that life cycle practices are continuously performed and perform as part of organizing.

\section{Handling local activities and interests}

\section{Local activities and interests (I) - towards a sustainability strategy}

Our empirical findings show ManuCorp's intentions to be regarded as an environmentally friendly company. For one, it recurrently highlighted the energy-saving capacity of its products 
in use (see for instance ManuCorp Annual Report, 2000, 2001, 2002, 2003). Furthermore, its representatives stressed the company's efforts to make its manufacturing process more efficient, thereby reducing the use of raw materials and energy. Energy use and efficiency were thus issues that were constantly put on the agenda at ManuCorp. To enable work with energy use and efficiency in a more systematic fashion, ManuCorp's senior management proposed and initiated a "sustainability strategy" in the early 2000s (Egels-Zandén \& Rosén, 2015), with the aim of decreasing the negative environmental impact of the company's own manufacturing as well as improving the environmental performance of its customers (ManuCorp Annual Report, 2012).

Measuring and calculating the reductions of the company's own energy use and $\mathrm{CO}_{2}$ emissions was not considered a major problem, as quantifications was common practice at the company. However, proving the environmental benefits for its customers, who use the company's products, proved to be challenging. The strategy documents described such improvements as a "business opportunity". Engineers however understood these descriptions as vague and struggled to, in terms of numbers and calculations, identify business cases that could support the customer-focused part of the strategy. How could they prove the reduction in negative impacts brought about when customers used ManuCorp's products? The engineers wanted more clarification as to what "the business case" really meant, trying to understand it in terms of numbers and measurements, as was a common practice at ManuCorp. Efforts were thus undertaken by the engineers to quantify the part of the strategy that focused on customers (Egels-Zandén \& Rosén, 2015).

\section{Local activities and interests (II) - developing life cycle assessment (LCA)}

Taking a step back, in the 1990s, roughly a decade prior to the initiation of the sustainability strategy, environmental issues at ManuCorp were managed by the company's "Environmental Department" and concerned mainly its own production and operations (Rosén, 2011). Consumers were becoming increasingly concerned about the environment and began to put pressure on manufacturers to become more environmentally-friendly. Faced with rising production costs and the potential of bad publicity, the consumer goods producers passed these concerns on to their suppliers (Report II, 2001). ManuCorp, like many other companies at that time, received many questions from customers and other stakeholders concerning the environmental impact of their products, and among these an increasing number specifically concerned LCA. In one LCA (master) thesis it was stated that

So far it is in most cases questions about environmental management systems, but the nature of the questions is slowly changing and becoming more product-related. Questions about LCA work and performed LCAs are becoming more frequent. (Report II, 2001)

In response to this interest, ManuCorp employees initiated also internal LCA studies, describing these as the "first steps towards understanding the life cycle" of its products with the help of environmental studies (internal ManuCorp material). 
The focus on questions regarding the environmental impact of products over their entire life cycle differed from the prevailing focus on the environmental impacts of specific units of production inside a company. The proponents of LCA at ManuCorp argued however that the LCA method allowed the company to calculate the environmental impacts of its products and build a new knowledge-base by applying a life cycle perspective to the environmental impacts of its operations and products in use. Given the company's strong engineering culture, which emphasized measurement and calculation, the prospect of developing and implementing a tool for measuring environmental impacts in a concise and systematic way played an important role in propelling life cycle work at ManuCorp.

To support the company in producing their first LCA studies, ManuCorp turned to academia. Initially, Master's students at a local university were invited to study and write about the company's LCA activities (Reports I-VIII). Soon after, the company sponsored a number of industry Ph.D. projects (Reports IX-XI, and XIII-XIV), eventually leading to the establishment of a formal industry-academia collaboration around LCA and life cycle related issues. For ManuCorp, the increasingly formalized interaction with the local university provided not only guidance and support in their endeavors to produce the company's first LCA studies. It also strengthened ManuCorp's claims of taking environmental issues seriously, by connecting them to the expertise and legitimacy associated with academia. For the university on the other hand, the partnership offered access to industry, including the possibility of undertaking empirical studies in a research field that was up and coming at the time, and increasingly popular among students on all levels. The interests of the company were thus translated into, and aligned with, the interests of the local university.

One of these first LCA studies conducted at ManuCorp identified the production of energy carriers (i.e., electricity, district heat, and heavy oil fuel) as the main source of air emissions. Furthermore, it highlighted the supply chain as the origin of great environmental impact in the product life cycle - what Baumann and Tillman (2004) describe as a "hotspot" - relating it specifically to air emissions such as carbon dioxide $\left(\mathrm{CO}_{2}\right)$.

The results of the study were acknowledged throughout the company and were published in the company's 2001 annual report, with the exhortation that they be used in the company to "ensure that improvement activities [were] focused on the areas with the greatest potential for environmental benefit" (ManuCorp Annual Report, 2001). This study received considerable attention throughout the company and brought home to many the potential of the LCA method (Report VII, 2008). In this way, the emergence of the idea of LCA was the result of reciprocal processes involving individuals inside and outside the organization. The idea eventually became packaged in ManuCorp's annual report, which further contributed to its circulation inside the organization, as well as outside the organization to external stakeholders.

Well before the emergence of "the sustainability strategy" or statements of "LCM" at ManuCorp, various actors were already engaged in activities on a local level in different parts of the organization and addressing various emergent concerns. The first mechanism of concern to us here is the handling of such local activities and concerns. In multinational and globally 
operating organizations, different actors (human and nonhuman) come and go on a continuous basis. As actors emerge and become connected to each other the practices of one group can readily influence otherwise uninvolved actors, prompting them to become involved (Callon, 1998). For example, the ambitions of ManuCorp's engineers to undertake LCA studies connected them to the interests and concerns of the local university of providing contemporary research topics of interest for their students. This and the many other efforts to address these emergent concerns should be seen as temporary in nature and they often become disconnected from one another.

\section{Connecting local activities and interests into action nets}

The second mechanism we wish to address concerns the knotting of local activities and interests into action-nets (Lindberg \& Czarniawska, 2006; Czarniawska, 2008). Over time, different local activities and interests may become connected to one another. For example, two programs of action - activities surrounding the development of a sustainability strategy and activities surrounding research on "greener products" - intersected when the CEO and several senior managers met to discuss proposals for the company's forthcoming anniversary. At the meeting, an R\&D manager suggested that the new, 'greener' products could serve as the business cases that had been sought for the sustainability strategy - a suggestion that was received positively by the attending managers (Egels-Zandén \& Rosén, 2015). The senior management meeting provided an opening for new connections to be made between elements that had so far been separated in time and space. However, as John Law (1992: 387) put it, "thoughts are cheap, but they don't last long, and speech lasts very little longer" -connections temporarily established through meetings can easily disintegrate again once the meeting ends. In the case of ManuCorp, however, the connections between the sustainability strategy and the research into 'greener products' developed and stabilized further in the aftermath of the senior management meeting, evidenced in a number of documents over the years in which the two were described as interlinked

These greener products are a part of the Sustainability Portfolio, that is, products, services and solutions that are developed to help customers decrease their environmental impact. (ManuCorp document "Energy efficient products", 2015)

As the new and explicit focus on the "greener" products became connected to the sustainability strategy (and what would eventually develop into a "sustainability portfolio" of products and services), energy efficiency and $\mathrm{CO}_{2}$ emissions were increasingly highlighted in the company's annual reports. This constituted a change in focus, from the previous breadth of focus on a large variety of environmental aspects (e.g., energy use, waste, water consumption etc.) when the idea of the 'life cycle' had been translated into LCA, to a narrower focus now, emphasizing and highlighting mainly energy use and $\mathrm{CO}_{2}$ emissions. This "editing” (Sahlin \& Wedlin, 2008) resulted in the materialization of new objects such as presentations and images of the sustainability strategy as well as related practices such as a new target for $\mathrm{CO}_{2}$ emission reductions and increased $\mathrm{CO}_{2}$ measurements. These objects helped to concretize and visualize the life cycle idea in the organization. ManuCorp thus concretized its focus on sustainability concerns not only in its own operations, but also in the context of customer-use of the 
company's products, illustrated for example by this quote by the Sustainability portfolio manager Mr. G

We have a large impact via our products' 'use phase', and we have an opportunity to make a large improvement from an environmental perspective by improving our products' performance in use.

The company wanted to become the spokesperson for sustainability in the chain of actors that were assumed to accompany the life cycle of its products.

In this regard, events such as the senior management meeting in the mid-2000s were important turning points. During such events, heterogeneous and local life cycle activities and interests were knotted together for the first time, and in the process were transformed from local activities into action-nets.

As distributed and heterogeneous elements interact, an action-net takes shape. However, activities and actors are likely to shift: activities can become connected and disconnected again, and the involvement of actors can vary as well over time, as they negotiate how to proceed and whether to proceed at all. In these ongoing deliberations and negotiations, the involved actors rely on differing understandings and are guided by shifting interests (Latour, 2005). An important but temporary result of these ongoing processes is the associations that are formed and reformed and that afford actors the capacity to act (Latour, 2005). In other words, agency is not given, but is afforded to elements in the emerging network through the ongoing processes of negotiation and mediation (Latour, 2005). Interestingly, although the classic literatures have suggested leaders and senior managers as the primary movers in organizations (e.g. Schein, 1985; Kotter, 1995) as possessing agency, our study shows that top managers only became enrolled in the action-net as the process unfolded. Rather than initiating life cycle work, ManuCorp's senior management, including the CEO, were connected to the emergent network, at which point their involvement and contributions stabilized the network further. Links and further connections formed across activities and interests as further elements became networked with another, giving rise to a larger network of actors (e.g. engineers, managers, suppliers, customers, standardizers) and activities and interests (e.g. reducing environmental impact, measuring environmental impact, selling products). Among other things, this links back to Bruno Latour's (1987) argument that translation concerns the manipulation of different interests. Because the hierarchical control of the translation process within and beyond the organization was limited and persuasion was pivotal, interest alignment was critical.

Whether or not a network constituted by temporarily aligned interests will grow and stabilize over time or grow weaker and unravel is never given once and for all, but is continually subjected to discussions, negotiations and mediations.

\section{Performing life cycle practices}

Being able to measure $\mathrm{CO}_{2}$ emissions, ManuCorp began in the mid-2000s to put demands on their major suppliers to "implement $\mathrm{CO}_{2}$ emissions reduction initiatives" (ManuCorp Annual 
Report, 2006) and to establish a "positive track record for sustainability" to qualify as a ManuCorp supplier (ManuCorp Annual Report, 2006). These attempts at influencing suppliers also included the adoption of an international standard for corporate greenhouse gas, issued by the Greenhouse Gas Protocol (GHG), which provides standards, guidance, tools and training for business and government to measure and manage climate-warming emissions. According to its homepage, the GHG Protocol provides "the world's most widely used greenhouse gas accounting standard" (https://ghgprotocol.org/about-us, accessed 190201). In the standard, emissions are divided into three categories: 1) direct greenhouse gas emissions (i.e., from fuel combustion, company vehicles, and fugitive emissions), 2) electricity indirect greenhouse gas emissions (i.e., from use of purchased electricity, heat and steam), and 3) other indirect greenhouse gas emissions, also known as 'value chain emissions' (e.g., embodied in the extraction and production of purchased materials and fuels) (GHG Protocol, n.d.). ManuCorp claimed the adoption of the GHG standard was meaningful to "gain a more complete understanding of the global warming impact of the company's activities" (ManuCorp Annual Report, 2007), as "the next step of transparent communication" to stakeholders (ManuCorp Annual Report, 2007), and a continuation of the type of $\mathrm{CO}_{2}$ emission reporting the company had conducted in the past. Furthermore, the results of the early LCA study on "the significance of $\mathrm{CO}_{2}$ emissions generated by the company's suppliers during the production of the components and materials purchased by the company," were connected to the decision to adopt the international standard. The adoption of the standard provided ManuCorp with the justification to influence and exert a certain amount of control over its suppliers, as $\mathrm{CO}_{2}$ emissions generated by suppliers were now categorized as ManuCorp's indirect emissions. By quantifying $\mathrm{CO}_{2}$ emissions, the standard and the LCA studies both supported and strengthened the claims made by ManuCorp about its work with sustainability, and supported the company in managing and controlling its suppliers in a way that had not been possible before. Connecting the business operations to an established standard helped even further to legitimize the company's efforts to respond to the sustainability challenge, perhaps even more than it decreased actual negative environmental impacts. Similarly, the adoption of the GHG standard shows the importance of further strengthening and building upon the previously connected local activities and interests. In "borrowing" (Latour, 1987) the GHG standard in order to further its own interests, ManuCorp lends its force to the standard's inventor and representatives, thereby connecting their interests in spreading the standard to the company's own interests in controlling its suppliers and, indirectly, its customers. This movement does the same for the standard, which, by adding another certified member is moving yet closer to becoming an important, if not indispensable, actor on the certifications market. Thereby, the two interests become intertwined, moving in the same direction. And the more indispensable the standard becomes, the more it contributes to fulfilling ManuCorp's goals of becoming widely recognized for its LCM and sustainability work. Thus, as these local activities and interests became connected, LCM gained momentum as a potential approach for including and addressing them.

\section{Resistance and adjustments}

However, suppliers were hesitant to provide ManuCorp with the data on energy use and $\mathrm{CO}_{2}$ emissions it demanded and needed to support its claims about its work with sustainability issues 
(Interview with Purchasing manager A, 2015). For one, this was not a common practice in the industry at that time, and secondly, suppliers were apprehensive about giving ManuCorp insights into their activities by providing such data. In response, ManuCorp revised its ambitions and decided to collect data only from those suppliers that were willing to share their data. Not surprisingly, the companies that supplied the data were ManuCorp's largest suppliers - anxious to maintain good relations with their important customer. ManuCorp convinced their suppliers, on the basis of its role as an important customer, to supply the data. And, in its 2009 Annual Report, the company presented them as the most important suppliers to monitor with regards to their energy use (ManuCorp Annual Report, 2009). The initial program to collect data from all suppliers encountered the suppliers' anti-programs and was subsequently translated further into the program "collect data from the most important suppliers" that consumed the largest amount of energy.

To sum up, ManuCorp's life cycle work now entailed attempts to influence its customers via the products they bought, and to influence the energy efficiency and $\mathrm{CO}_{2}$ emissions of certain important suppliers. ManuCorp became influential in a growing LCM network by involving other actors in its supply chain and among its customers through applying a life cycle perspective to the environmental performance of its production, its products and its products' end-use.

\section{Ongoing emergence of life cycle practices - proving environmental impact}

The emergence of the sustainability strategy and of several new 'greener' products created a demand for even more knowledge about the environmental performance and impact of ManuCorp's products. A few years after the launch of the sustainability strategy, Mr. A was hired as an LCA project manager in the R\&D department. He highlighted the need to build knowledge of the environmental performance and the impacts of ManuCorp's products, especially to respond to top management needs. Consequently, an increasing number of LCA studies was undertaken in the department, in order to "[build] methods and methodology, and to spread life cycle thinking in the company" (Interview with Mr. A, 2017). More specifically, one large-scale LCA study was conducted and supplemented by ten minor LCA studies in an attempt to cover the whole breadth of the company's product portfolio and build a knowledge base for further development work. The aim was to "understand environmental impact in a new way and not to answer a specific question or to serve as a marketing ploy" (Interview with Mr. A., 2017). The large-scale LCA study was based on the ISO 14000 standard series, an international LCA standard, with the aim of consolidating the company's LCA procedures and methods. These standards provide principles and a framework for LCA, as well as related requirements and guidelines (ISO, 2006). Previous LCA studies had been considered somewhat limited in applicability, as too many divergent methodological choices had been made that rendered them less useful after their completion, in turn generating a lack of credibility (Interview with Mr. A, 2012). Connecting ManuCorp's burgeoning number of LCA studies to the external standard gave rise to new life cycle work at the company as the standard, while presenting LCA as a sound and meaningful method to use, also required actions to be undertaken for the company to show that it fulfilled the standard's requirements. 
This increased work was mainly conducted over a five-year period around 2010. During this time, the vocabulary at ManuCorp changed from focusing on the "environment" to focusing on "sustainability", accompanied by terms such as "LCM" and "life cycle thinking" (ManuCorp Annual Report, 2008, 2009). Moreover, the annual reports referred to the "cradle to grave" approach and highlighted the importance of "understanding and acting on environmental impacts through the product life cycle" (ManuCorp Annual Report, 2009). A year later, in 2010, the annual report spoke of life cycle thinking as pivotal in the creation of a competitive advantage, "in that it allow[ed] for the quantification of the environmental impact, the reduction of which can generate cost savings as well as reduced environmental impact for the company and its customers" (ManuCorp Annual Report, 2010). The same report also highlighted the role of LCM research in "developing and adapting environmental accounting tools, to support environmentally proactive decision-making", further underlining the fact that the life cycle idea had gained enough recognition and legitimacy in the organization.

These developments can be understood by pointing out that translations often unfold through the creation of a problem and the subsequent offering of a solution (Latour, 1987: 114-115). In our case, actors influenced various interests by presenting and highlighting emissions as a major problem while at the same time presenting readily available solutions to such a problem (corporate environmental management, for instance) as outdated. Instead, LCM was presented as a new and improved solution, involving changes to the supply chain and to communications and including claims of helping to build better partnerships for the benefit of all. Over time, this became the specific solution of all relevant actors through successful translations. In the ManuCorp case, broad interests were reinterpreted to particular issues (i.e. providing proof of environmental impact), binding different actors together and rendering differences invisible at least temporarily.

Notwithstanding the development of the 'greener products' and their incorporation as business cases into the sustainability strategy, internal as well as external stakeholders continued to raise questions and concerns, some requesting a further concretization of the strategy. At that point, some product development efforts had resulted in products that were deemed to have a more environmentally-friendly profile than any similar products on the market. Even so, there was a wish to define such environmentally-related product chains more clearly, and to enhance these product offerings.

At that point, LCA studies had found that company products had large negative environmental impacts specifically in the use phase, suggesting that the company could help reduce these impacts through improving the "environmental use profile" of its products (Interview with Mr. $\mathrm{G}, 2012$ ). In this case, LCA results were used to account for environmental activities and impact outside of the company's production facilities and even beyond the traditional scope of the organization. As Mr. G commented, ManuCorp had previously emphasized having good control and management of internal environmental aspects, and it was now expanding its engagement further along the product chain. 
This development resulted in the development of a "sustainability portfolio", which was developed over several years. From the beginning, a central question for the sustainability portfolio core team, comprising Mr. G. and three so-called sustainability representatives, each working in one of the three divisions of the company, concerned how to make the portfolio credible. They believed that the only way this would be possible was by quantifying the environmental impact of the products. As Mr. G. recounts

We seek to explain, in numbers, the environmental savings that these solutions provide /.../ and explain how we have calculated this. (Interview, Mr. G, 2012)

In this case, credibility was understood as relying on the ability to quantify, measure, and follow up on goals, savings, and sales, to name a few, and to communicate these results to customers and other potential stakeholders.

A challenge encountered in this process was brought about by the conflicting views and expectations of top management and the engineers on the operational levels of the organization (Interview with Mr. G, 2012). Since there were no existing standards for measuring the environmental performance of company products in use, they had to develop a new method for measuring it. Top management had asked that the method should not be 'over-engineered,' that is, not too complicated nor too time or resource consuming. However, the engineers developing the measurements for the portfolio wanted to present their measurements to customers only once they were absolutely confident about the precise results. While top management decided on the direction and allocation of resources, engineers in operations conducted the development work, thus shaping the results and formation of the portfolio in the process. The sustainability core team found itself in the middle of these diverging interests. As such, Mr. G. described that

The methods become very complicated, and I try to handle this balancing, and I have highlighted this in my communication, both towards top management and towards the engineers. This is one of the challenges in this project. (Interview with Mr. G, 2012)

Initially, the team working on the sustainability portfolio was in direct contact with employees on the operational level in different parts of the organization, such as marketing and product development to discuss the development of 'credible' concepts, creating connections between employees throughout ManuCorp who were interested in similar issues. Therefore, and as a necessity in going from a project to a new type of organization to handle the portfolio, the "Sustainability department"i team continued by holding discussions mainly with managers from different departments (Interview with Mr. G, 2012). Soon after the sustainability portfolio project was approved by top management, the manager of the Sustainability department telephoned Mr. A (also part of the previous discussions), requesting help from the R\&D department in developing a method for the assessments, and with conducting the assessments. From then on, the R\&D department had about nine months to complete the assessments of ten products, so that they could be presented, with claims of environmental credentials, at the launch of the sustainability portfolio. One sustainability representative explains 
[I]f you have only an idea about [a product] being environmentally-friendly, then that's far from enough. You have to prove it, you have to have the proof and you have to make clear assumptions, and document everything. (Interview, Mr. O, 2012)

After years of LCA experience, Mr. A explained that they had gained 'a feel' for LCA results (Interview with Mr. A, 2017). Mr. A and his team realized that they could not conduct full LCAs for each product, as it would be too resource and time consuming. It took three months of "twisting and turning on different variants of LCA" and carbon footprint calculations (i.e., PAS2050, a standard and method for calculating the $\mathrm{CO}_{2}$ emissions of goods and services from a life cycle perspective; SGS, n.d.), as well as input from external consultants, until they "felt comfortable with a method" for the measurements (Interview with Mr. A, 2017). Subsequently, they applied the new method to the products that were launched as part of the sustainability portfolio (Interview with Mr. A, 2017). ManuCorp's annual report described it as a way to "broaden the scope of the company's targets to include not only company operations but also its suppliers, logistics and customers" and as a way to help customers reduce their environmental impact (ManuCorp Annual Report, 2012).

The launch of the sustainability portfolio brought with it requirements for the development of new products, as well as their assessment for the portfolio, resulting in a large number of environmental assessments undertaken during the two years after the launch (Interview with Mr. A, 2017).

But even as emergent activities and interests become intertwined and knotted together, work continues. This is related to the third mechanism, the performativity of life cycle practices. Life cycle practices do not simply prescribe what should be done in certain situations. They actively intervene in situations and thereby contribute to the enactment of normative realities (see also Gehman et al., 2013). Environmental data (e.g. energy use, material use) need to be gathered for LCA studies, environmental information and 'good examples' need to be identified and processed for annual reports, organizational processes and structures need to be built to manage the sustainability portfolio, to mention a few. There is also the continuous work of formulating and visualizing this type of information so that it can be spread in the organization, both in text and in oral communication with internal stakeholders (see section Spreading the life cycle idea for more details). Summarily stated, life cycle work is an ongoing practice through which an organization's life cycle practices are performed over time.

\section{Spreading the life cycle idea}

Parallel to the launch of the sustainability portfolio, ManuCorp launched another strategy, its stated aim being to "tackle the significant greenhouse gas impacts in the full life cycle and the full value chain of the company's products and solutions" (ManuCorp Annual Report, 2012). This 'climate strategy' targeted reduced energy consumption not only in the company's own operations, but also in the supply chain, emphasizing increased sales of the sustainability portfolio (i.e., a customer focus) (Interview with Ms. J, 2012). Ms. J, working in the Sustainability department, described how ManuCorp already had activities addressing energy 
use and efficiency in its own production, though explicit company goals had been lacking. The increased availability of new standards and ongoing technological developments were also presented as a basis for updating the climate strategy, which represented an outgrowth of the preceding adoption of the GHG standard (Interview with Ms. J, 2012). Against this background, Ms. J was assigned to 'upgrade' the company's climate strategy, while collaborating with external parties to benchmark the strategy against external expectations and demands. Such public external collaboration generated a "strong sales argument" for ManuCorp (Interview with Purchasing manager B, 2014). With explicit climate goals, Ms. J explained, it would be possible to illustrate internally and externally what the company wanted to achieve, enabling company employees to engage in activities related to the company targets. Furthermore, she explained, the company had "made itself a name" in this field, largely thanks to the CEO and his engagement, providing a basis for the ongoing environmental performance of the company (Interview with Ms. J, 2012).

In the climate strategy, the company also implemented another ISO standard, specifically for energy management, that encompassed the company's own manufacturing processes, as well as targets for energy-intensive suppliers (e.g., implementing energy management systems) (Interview with Sustainable supply chain manager, 2014). This led to the targeting of the supply chain via the use of external standards again addressing energy use and $\mathrm{CO}_{2}$ emissions.

As life cycle work unfolds, one effect is that the life cycle idea becomes packaged as a resource for legitimating the spread of life cycle practices throughout the organization and beyond. For instance, life cycle work was from the beginning seen as concerning a rather narrow focus undertaking LCA studies. This can be seen as pragmatic and the sensical thing to do as life cycle practices would be hard to manage otherwise. At the same time, we realized that life cycle work is hard to confine to one place and time. As life cycle work becomes packaged into models, annual reports or other documents they spread even more easily. The annual reports published by ManuCorp for instance embodied the life cycle idea that could travel to and be translated in other parts of the organization, and by external actors. They were the result of life cycle work, but also shaped this work as it spread in a rhizome-like fashion (Nicolini, 2010). And, as Georg (2005) noted, environmental reports do not only account for corporate behavior, but also perform it "by shaping interpretations and understandings and /.../ by committing resources that /.../ direct and shape attention" (p. 146).

From a translation sociology perspective, this spreading is unsurprising (see Czarniawska \& Sevón, 1996; 2005; Diedrich, 2004; Gehman et al., 2013). Once the sustainability portfolio became available, stakeholders began associating with it and relating it to other parts of the organization, greatly supporting the further growth and durability of the emergent network at the company. However, as Law (1992) cautioned, such durability is not given, but is the temporary result of continuous interactions. At this point, our narrative ends - the processes of translation continue though. 


\section{Discussion and implications}

Our observations outlined above illuminate the significant work that is undertaken as the life cycle idea is translated into ManuCorp, eventually resulting in the emergence and performance of new life cycle practices at the company and beyond. We refer to this work as life cycle work, by which we mean the work that is undertaken at any moment as life cycle practices emerge and are performed, as well as the effects life cycle practices perform and provoke as they spread in the organization. This work is not homogeneous but varies over time. To theorize around this work, we proposed four processes involved in the emergence and performance of life cycle practices: handling local activities and concerns, knotting local activities into action nets, performing life cycle practices and spreading the life cycle idea further.

We asked: how do life cycle practices emerge and how are they performed over time? Our analysis of the making of the sustainability portfolio illustrated that it emerged as the interests of actors and proposed life cycle practices became intertwined, generating activities and interests. Further down the road, as these local activities and interests became knotted together into an action-net, the sustainability portfolio gained energy as a device for encompassing and enacting the life cycle practices these activities and interests had provoked. The sustainability portfolio and its life cycle idea became invoked as a way of legitimating the development of new life cycle practices in other locales. The use and results of LCA studies also provided legitimization for ManuCorp's life cycle practice. Parallel, and intertwined with the sustainability portfolio, the life cycle activities at the company developed, from LCA studies, to the company making explicit claims of LCM. This development illustrates the translation process taking place, and also illustrate a stabilization of the life cycle practice.

Taken together, our observations suggest that life cycle work is a continuous, relational and interactive process. The four processes we describe here are not exhaustive of all possibilities. Rather, they are meant to indicate the kind of life cycle work involved in the emergence and performance of life cycle practices. In the following, we reflect on some opportunities and challenges that our theory of life cycle work implies for future research within the management and organizational studies as well as for LCM research.

One question concerns the origins of LCM. If we had commenced our study at the point in time when the senior management team including the CEO held its meeting (the example described earlier), we could have easily attributed the emergence of the LCM-based sustainability portfolio exclusively to the agency and efforts of the senior managers. We would have missed that local activities and interests had been around for a few years in various parts of the organization, well before any formalized life cycle practices were put in place or any executive leaders became enrolled. More generally, and in line with previous studies of other organizational issues, life cycle work is likely to be ongoing, independent of whether leaders are involved or not. Thus, independent of whether life cycle practices are oriented towards the positive, away from the negative, or both, such judgements are normatively laden, and thus likely to involve life cycle work. 
The performativity of life cycle work encourages us to think about LCM as a collective, temporarily stabilized system. Performativity can be expected to be an integral part of life cycle work in a world with fluid boundaries and shifting participation. One implication is that organizations may find themselves in a position where they are faced with an even larger complexity and heterogeneity with respect to life cycle practices than was the case with ManuCorp. This should not be seen as a problem to be removed, but as lying at the heart of life cycle work: it is through the continuing negotiations, mediations and reconfigurations that life cycle practices are performed and perform.

At a rhetorical level, our material shows how LCM became connected to universal problems associated with saving the environment, and not simply a problem pertaining to ManuCorp only. This contributed to mobilizing sufficient support for organizational change and is in line with Røvik's (2002) argument that the spread of management fashions depends on the extent to which they are associated with rational values in modern society, such as renewal, efficiency and effectiveness. But this act of labelling also had material consequences, because the sort of universal problem that LCM would resolve was closely related to the particular way it was translated into changes to work methods or organization. At ManuCorp, we found that efforts to avoid negative and unwanted outcomes to save the environment such as high levels of energy consumption, for example, triggered life cycle work. Interestingly, and in contrast to HowardGrenville et al.'s (2006) study on "sustainability concerns", which showed that those involved in sustainability work envisioned the aspirational possibilities sustainability afforded, our study suggests that concerns regarding life cycle work emerged not only because of visionary aspirations that were aspired to, but also as a response to problems. Life cycle work at ManuCorp was, for instance, driven by a wish to avoid undesirable outcomes (i.e. reducing $\mathrm{CO}_{2}$ emissions in ManuCorp's production facilities) as well as by achieving positive results (i.e. ManuCorp's products actually reducing customer's $\mathrm{CO}_{2}$ emissions in use). Our material suggests that the performativity of life cycle work is such that similar dynamics unfold no matter if the intent is to achieve desirable outcomes or to avoid negative ones, and that any subsequent life cycle work requires further negotiations and reworkings. Our findings are thus in line with Weaver, Trevino and Cochran (1999) who had earlier found that these orientations can operate concomitantly. This is likely to provoke further work as an action net is stretched and pulled in multiple directions and some activities and interests may even become disconnected through the tensions between aspirations and compliance with rules. Our study raises questions about the appropriate methods for studying life cycle practices.

In our investigation, we had access to considerable archival, interview and ethnographic data over a period of seven years. Understanding the emergence of the sustainability portfolio over time and in action (Czarniawska, 2004), we could see that years before any official program was launched, activities had been undertaken and interests had been voiced on multiple occasions and in many places. This observation points to the benefits of a translation sociology approach in capturing important aspects of emerging processes over time, something that the life cycle literature has largely neglected. Above all, such an approach makes it possible to identify and follow life cycle activities and connected interests that may not be immediately and easily visible for some time. 
Employing a translation perspective to the study of LCM has given us the opportunity to move away from stories of ready-made systems and methods that appear to be solid and are implemented and adopted in organizations, because of their inherent functional superiority. Yet, although such systems and methods appear functionally superior and solid, they are not necessarily so. They can be described in the words of Latour (2013) as "phantoms" - creatures that are there temporarily, only to be gone the next moment. In any given moment that we focus on such systems or methods, things seem unchangeable and 'organized-for-good' (Czarniawska, 2004: 780) - implemented - the processes of organizing, however, continue. To paraphrase Latour (2013: 44), the sustainability portfolio is what is talked about, when the organizing has already stopped and has disappeared from purview. The life cycle researchers have largely been interested in the phantoms, instead of the organizing processes that may result in the phantoms appearing and disappearing in the first place. Yet many interesting issues stand to emerge if one takes a step back to explore the dynamics of the organizing processes unfolding before the systems and methods are in place - appear to be solid. Thus, while we have taken a first step in that direction, further studies exploring in depth the processes leading to the emergence and stabilization of LCM and other life cycle "phantoms" over time and in different settings is called for.

Finally, as holds true for other qualitative processual research, our study provokes the question: To what extent can we expect our findings to apply to other organizations? The sociology of translation warns us that organizing is by necessity 'local' and situated, and that the creation and maintenance of uniform universal truths must be justified empirically and not taken for granted (Latour, 1987). The value of qualitative studies is however to support us in further developing and refining our understanding of phenomena by offering insights that allow others to see things they could not have seen before (see, e.g. Tsoukas, 2009).

\section{Conclusions}

The translation sociology agenda for 'greener' resources, climate strategies and sustainability models are part of a growing desire among researchers to understand the dynamics of 'sustainability concerns' as part of organizing. Over the years, such concerns have been understood differently in and around organizations. Overall, we found that classic, normative perspectives have stopped short of understanding life cycle thinking as situated in practices. To address this gap, we introduced the concept of life cycle practice and approached the topic from a sociology of translation perspective to understand the processes involved in their emergence and spread. Drawing on our study of the sustainability portfolio at ManuCorp, we proposed the concept of life cycle work, which includes four important and interrelated processes. Life cycle work includes dealing with local activities and interests, connecting local activities and interest into action nets, performing life cycle practices, and spreading life cycle ideas. Our analysis illustrates the continuous work that is involved in the emergence and performance of life cycle practices as well as the work that life cycle practices perform and give rise to in organizations. The sociology of translation inspired approach outlined here suggests that we cannot better understand life cycle practices by exploring their 'implementation' or 'diffusion' only, or by regarding them solely as the doings of heroic leaders and entrepreneurs only. Instead, we need to follow the discussions, negotiations and 
ongoing reconfigurations through which life cycle practices are performed and perform. By doing so, we hope that novel ways of thinking about the role of LCM in organizations will emerge.

\section{References}

\section{Primary sources}

ManuCorp Annual Reports, 2000, 2001, 2001, 2003, 2004, 2005, 2006, 2007, 2008, 2009, 2010, 2011, 2012, 2013, 2014.

Report I. LCA study, M.Sc. (1996).

Report II. LCA study, M.Sc. (2001).

Report III. LCA study, M.Sc. (2001).

Report IV. LCA study, M.Sc. (2002).

Report V. LCA study, M.Sc. (2003).

Report VI. LCA study, M.Sc. (2006).

Report VII. LCA study, M.Sc. (2008).

Report VIII. LCA study, M.Sc. (2008).

Report IX. LCA study, Lic. (2009).

Report X. LCM study, Ph.D. (2011).

Report XI. LCM study, Ph.D. (2012).

Report XII. LCA study, M.Sc. (2012).

Report XIII. LCM study, Lic. (2014).

Report XIV. LCM study, Lic. (2014).

\section{Secondary sources}

Baumann, H. (2000). Introduction and organisation of LCA activities in industry. The International Journal of Life cycle Assessment, 5(6), 363.

Baumann, H., \& Tillman, A. M. (2004). The Hitch Hiker's guide to LCA: An orientation in life cycle assessment methodology and application. Lund, Sweden: Studentlitteratur.

Benetto, E., Gericke, K., \& Guiton, M. (Eds.) (2018). Designing sustainable technologies, products and policies: From science to innovation. SpringerOpen.

Bergström, O., \& Diedrich, A. (2011). Exercising social responsibility in downsizing: Enrolling and mobilizing actors at a Swedish high-tech company. Organization Studies, 32(7), 897-919.

Bey, N. (2018). Life cycle management. In M. Hauschild, R. Rosenbaum, \& S. Olsen (Eds.), Life cycle assessment: Theory and practice (pp. 519-544). Cham, Switzerland: Springer International.

Bjarnar, O., \& Kipping, M. (1998). The Marshall Plan and the transfer of US management models to Europe: An introductory framework. In Kipping, M. \& O. Bjarnar (Eds.), The Americanization of European Business. London: Routledge.

Callon, M. (1986). Some elements of a sociology of translation: Domestication of the scallops and the fishermen of St Brieuc's Bay. In J. Law (Ed.), Power, action and belief (pp. 196-233). London, UK: Routledge. 
Callon, M. (1998). Introduction: the embeddedness of economic markets in economics. The Sociological Review, 46 (1 suppl), 1-57.

Charmaz, C. (2006). Constructing grounded theory: A practical guide through qualitative analysis. London, UK: SAGE.

Colens, H. (2017). Life cycle thinking is the key to unlocking the Circular Economy. The Parliament Magazine, 20 January 2017. Retrieved from https://www.theparliamentmagazine.eu/articles/partner_article/braskem/life-cycle-thinkingkey-unlocking-circular-economy

Czarniawska, B., \& Joerges, B. (1996). Travels of ideas. In B. Czarniawska \& G. Sevón (Eds.), Translating organizational change (pp. 13-48). Berlin, Germany: Walter de Gruyter.

Czarniawska, B., \& Sevón, G. (1996). Translating organizational change. Berlin, Germany: Walter de Gruyter.

Czarniawska, B. (2004). On space, time, and action nets. Organization, 11, 773-791.

Czarniawska, B., \& Sevón, G. (2005). Global ideas: How ideas, objects and practices travel in the global economy. Copenhagen, Denmark: Copenhagen Business School Press.

Czarniawska, B. (2008). A theory of organizing. Cheltenham: Edward Elgar.

Diedrich, A. (2004). Engineering knowledge. How engineers and managers practice knowledge management. Gothenburg: BAS Publishing ( $\mathrm{PhD}$ thesis).

Diedrich, A., Eriksson-Zetterquist, U., Ewertsson, L., Hagberg, J., Hallin, A., Lavén, F., Lindberg, K., Raviola, E., Rindzeviciute, E., \& Walter, L. (2013). Exploring the performativity turn in management studies. Gothenburg: University of Gothenburg, GRI-report 2013:2.

DiMaggio, P. J., \& Powell, W. W. (1983). The iron cage revisited: Institutional isomorphism and collective rationality in organizational fields. American Sociological Review, 147-160.

Egels-Zandén, N., \& Rosén, M. (2015). Sustainable strategy formation at a Swedish industrial company: Bridging the strategy-as-practice and sustainability gap. Journal of Cleaner Production, 96, 139-147.

Ehrenfeld, J. R. (1997). The importance of LCAs - warts and all. Journal of Industrial Ecology, 1(2), 41-49.

Finkbeiner, M. (Ed.) (2011). Towards life cycle sustainability management. Dordrecht: Springer.

Flyvbjerg, B. (2006). Five misunderstandings about case-study research. Qualitative Inquiry, 12(2), 219-245.

Gehman, J., Treviño, L. K. \& Garud, R. (2013). Values work: A process study of the emergence and performance of organizational values practices. Academy of Management Journal, 56(1), 84-112.

Georg, S. (2005). Corporate environmental reporting: Constructing the environment and corporate environmental performance. In L. Füssel (Ed.), Corporate environmental governance: Perspectives on organizing and communication (pp. 145-178). Lund, Sweden: Studentlitteratur.

Greenhouse Gas (GHG) Protocol (n.d.). A corporate accounting and reporting standard: Revised edition. Retrieved 2018-06-15 from https://ghgprotocol.org/sites/default/files/standards/ghg-protocol-revised.pdf Heiskanen, E. (2002). The institutional logic of life cycle thinking. Journal of Cleaner Production, 10(5), 427-437. 
Hellweg, S., Koehler, A., \& Rebitzer, G. (2008). LCM2007-From analysis to implementation. The International Journal of Life cycle Assessment, 13(1), 7-9.

Hoffman, A. J. (2001). Linking organizational and field-level analyses: The diffusion of corporate environmental practice. Organization \& Environment, 14(2), 133-156.

Hoffman, A. J. (2003). Linking social systems analysis to the industrial ecology framework. Organization \& Environment, 16(1), 66-86.

Howard-Grenville, J. A. (2006). Inside the "black box": How organizational culture and subcultures inform interpretations and actions on environmental issues. Organization \& Environment, 19(1), 46-73.

Howard-Grenville, J., Buckle, S. J., Hoskins, B. J., \& George, G. (2014). Climate change and management. Academy of Management Journal, 57(3), 615-623.

Hunkeler, D., Saur, K., Rebitzer, G., Finkbeiner, M., Schmidth, W. P., Jensen, A., ... Christiansen, K. (2003). Life cycle management. SETAC Press.

ISO, International Organization for Standardization (2015). ISO 14001 key benefits. Retrieved from

https://www.iso.org/files/live/sites/isoorg/files/standards/docs/en/iso_14001_key_benefits.pdf ISO, International Organization for Standardization (2006). ISO standards for life cycle assessment to promote sustainable development. Retrieved from https://www.iso.org/news/2006/07/Ref1019.html

Kotter, J.P. (1995). Leading change: Why transformation efforts fail. Harvard Business Review, March-April: 59-67.

Langley, A. (1999). Strategies for theorizing from process data. Academy of Management Review, 24(4), 691-710.

Law, J. (1992). Notes on the theory of the actor-network: Ordering, strategy, and heterogeneity. Systems Practice, 5(4), 379-393.

Latour, B. (1986). The powers of association. In J. Law (Ed.), Power, action and belief: A new sociology of knowledge? (pp. 264-280). London, UK: Routledge.

Latour, B. (1987). Science in action: How to follow scientists and engineers through society. Cambridge, MA: Harvard University Press.

Latour, B. (2005). Reassembling the social. Oxford, UK: Oxford University Press.

Latour, B. (2013). "What's the story?" Organizing as a mode of existence. In D. Robichaud \& F. Cooren (Eds.), Organization and Organizing: Materiality, agency, and discourse (pp. 6175). New York: Routledge.

Lindberg, K. \& Czarniawska, B. (2006). Knotting the action net, or organizing between organizations. Scandinavian Journal of Management, 22, 292-306.

Linnanen, L, Bostrom, T., \& Miettinen, P. (1995). Life cycle management: Integrated approach towards corporate environmental issues. Business Strategy and the Environment, 4(3), 117127.

Meima, R. (2002). Corporate environmental management: Managing (in) a new practice area (Doctoral dissertation). Lund, Sweden: Lund Business Press.

Millar, C., Hind, P., \& Magala, S. (2012). Sustainability and the need for change: Organizational change and transformational vision. Journal of Organizational Change Management, 25(4), 489-500. 
Mortimer, C. (2011). Enablers and barriers to adoption of life cycle management. New Zealand: NZLCM Centre Working Paper Series: Paper 1(11).

Nicolini, D. (2010). Medical innovation as a process of translation: A case from the field of telemedicine. British Journal of Management, 21(4), 1011-1026.

Nicolini, D. (2012). Practice theory, work, and organization: An introduction. Oxford: Oxford University Press.

Nilsson-Lindén, H., Baumann, H., Rosén, M., \& Diedrich, A. (2018). Organizing life cycle management in practice: Challenges of a multinational manufacturing corporation. The International Journal of Life cycle Assessment, 23(7), 1368-1382.

Poikkimäki, S. (2006). Look closer to see further: Exploring environmental life cycle management, LCM (Doctoral dissertation). Jyväskylä, Finland: University of Jyväskylä.

Rebitzer, G (2015). Introduction: Life cycle management. In G. Sonnemann \& M. Margni (Eds), Life cycle management (pp. 3-6). Dordrecht, The Netherlands: Springer.

Remmen, A., Jensen, A. A., \& Frydendal, J. (2007). Life cycle management: A business guide to sustainability. Nairobi: UNEP/SETAC.

Rex, E., \& Baumann, H. (2007). Individual adaptation of industry LCA practice: Results from two case studies in the Swedish forest products industry. The International Journal of Life cycle Assessment, 12(4), 266.

Rex, E. (2008). Marketing for life cycle thinking. Ph.D. thesis, Chalmers University of Technology, Gothenburg, Sweden.

Rosén, M. (2011). The practice of strategy formation: Opening the green box (Doctoral dissertation). Göteborg, Sweden: BAS.

Røvik, K. A. (2002). The secrets of the winners: Management ideas that flow. In K. SahlinAndersson \& L. Engwall (Eds), The expansion of management knowledge. Stanford, CA: Stanford Business Books.

Sahlin, K. \& Wedlin, L. (2008). Circulating ideas: Imitation, translation and editing. The Sage Handbook of Organizational Institutionalism, 218, 242.

Schein, E. (1985). Organizational culture and leadership. San Francisco, CA: Jossey-Bass.

Schmidt, K. (2013). Social practices - A new focus in LCM. Proceedings of the 6th International Conference on Life Cycle Management, Gothenburg, Sweden.

SGS (n.d.). Carbon footprint. Retrieved 2018-09-11 from https://www.sgs.com/en/sustainability/facilities-and-production/product-and-

packaging/carbon-footprint/pas-2050-carbon-footprint

Silverman, D. (2011). Interpreting qualitative data: A guide to the principles of qualitative research (4th ed.). London, UK: SAGE.

Sonnemann, G., \& Margni, M. (Eds.) (2015). Life cycle management. The Netherlands: Springer.

Sonnemann, G., Gemechu, E. D., Remmen, A., Frydendal, J., \& Jensen, A. A. (2015). Life Cycle Management: Implementing Sustainability in Business Practice. In G. Sonnemann \& M. Margni (Eds.), Life cycle management. Netherlands: Springer.

Strothmann, P., Bricout, J., Sonnemann, G., \& Fava, J. (2015). Communication and collaboration as essential elements for mainstreaming life cycle management. In G. Sonnemann \& M. Margni (Eds.), Life cycle management. Netherlands. Springer. 
Swedish Life Cycle Centre (SLC) (2016). Goda Exempel - Inspiration till energieffektivisering genom hela värdekedjan. SLC report, 2016:7.

Tsoukas, H. (2009). Craving for generality and small-N studies: A Wittgensteinian approach towards the epistemology of the particular in organization and management studies. The Sage Handbook of Organizational Research Methods, 285-301.

Van de Ven, A. H. \& Poole, M. S. (1995). Explaining development and change in organizations. Academy of Management Review, 20, 510-540.

Weaver, G. R., Trevino, L. K., \& Cochran, P. L. (1999). Integrated and decoupled corporate social performance: Management commitments, external pressures, and corporate ethics practices. Academy of Management Journal, 42(5), 539-552.

Wæraas, A., \& Nielsen, J. A. (2016). Translation theory 'translated': Three perspectives on translation in organizational research. International Journal of Management Reviews, 18(3), 236-270.

Weick, K. E. (1979). The social psychology of organizing. Columbus, OH: McGraw-Hill Humanities.

Welford, R. (2003). Beyond systems: A vision for corporate environmental management for the future. International Journal of Environment and Sustainable Development, 2(2), 162-173. Westkämper E., Alting, L., \& Arndt, G. (2001). Life cycle management and assessment: Approaches and visions towards sustainable manufacturing. Proceedings of the Institution of Mechanical Engineers, Part B: Journal of Engineering Manufacture, 215(5), 599-626.

\footnotetext{
${ }^{\mathrm{i}}$ The Environmental department had previously reorganized into a Sustainability department.
} 